\title{
Maternal diet alters expression of specific PPAR $\alpha$ transcripts in the hearts of their female offspring
}

\author{
Joanne Slater-Jefferies, Emma Phillips, Karen Lillycrop, Gemma Legg, Paul Townsend, \\ Mark Hanson and Graham Burdge \\ University of Southampton, Southampton, Hants, UK
}

Reduced PPAR $\alpha$ expression, and hence impaired fatty acid $\beta$-oxidation and deposition of TAG in the myocardium, is associated with cardiomyopathy $^{(1)}$. Restricting dietary protein intake of pregnant rats induces altered cardiovascular function in the offspring ${ }^{(2)}$. The present study has investigated the effect of feeding a protein-restricted (PR) diet to pregnant rats on the expression of PPAR $\alpha$ and its target genes involved in fatty acid $\beta$-oxidation in the heart of the offspring.

Female rats were fed a control $(180 \mathrm{~g}$ protein $/ \mathrm{kg})$ or PR $(90 \mathrm{~g}$ protein $/ \mathrm{kg}$ ) diet throughout pregnancy. Offspring (seven to twelve per dietary group) were fed the control diet containing $4\left(\mathrm{FAT}_{4}\right)$ or $10\left(\mathrm{FAT}_{10}\right) \mathrm{g}$ fat $/ 100 \mathrm{~g}$ from weaning until postnatal day 105 . Hearts were collected and frozen in liquid $\mathrm{N}_{2}$. mRNA expression of PPAR $\alpha$ and its target genes carnitine palmitoyl transferase (CPT)-1 and acyl-CoA oxidase (AOX) was measured by real-time RT-PCR ${ }^{(3)} .5^{\prime}$ RNA ligase-mediated rapid amplification of cDNA ends was used to identify the PPAR $\alpha$ transcripts. TAG concentration was determined by $\mathrm{GC}^{(3)}$. Statistical comparisons were by a general linear model.

Two PPAR $\alpha$ transcripts corresponding to different $5^{\prime}$ regulatory regions (termed P1 and P2) were identified. Post-weaning diet (PWD) did not alter any of the outcome measures. Based on marginal means, P1 expression was $12 \%$ lower and P2 expression was $14 \%$ lower in offspring of PR dams. AOX and CPT-1 expression was also lower (9\% and $8 \%$ respectively) in the offspring of PR dams. Based on marginal means, total TAG concentration was $55 \%$ higher in the offspring of PR dams compared with controls.

\begin{tabular}{|c|c|c|c|c|c|c|c|c|c|c|c|}
\hline & \multicolumn{4}{|c|}{ Control } & \multicolumn{4}{|c|}{ PR } & & & \\
\hline & \multicolumn{2}{|c|}{$\mathrm{FAT}_{4}$} & \multicolumn{2}{|c|}{$\mathrm{FAT}_{10}$} & \multicolumn{2}{|c|}{$\mathrm{FAT}_{4}$} & \multicolumn{2}{|c|}{$\mathrm{FAT}_{10}$} & \multicolumn{3}{|c|}{$P($ ANOVA $)$} \\
\hline & Mean & $\mathrm{SE}$ & Mean & $\overline{\mathrm{SE}}$ & Mean & $\overline{\mathrm{SE}}$ & Mean & $\overline{\mathrm{SE}}$ & MD & PWD & $\mathrm{MD} \times \mathrm{PWD}$ \\
\hline \multicolumn{12}{|l|}{ mRNA expression* } \\
\hline PPAR $\alpha$ P1 & 0.81 & 0.05 & 0.74 & 0.01 & 0.69 & 0.01 & 0.67 & 0.02 & $<0.0001$ & NS & NS \\
\hline $\operatorname{PPAR} \alpha \mathrm{P} 2$ & 0.72 & 0.04 & 0.65 & 0.01 & 0.60 & 0.01 & 0.58 & 0.01 & 0.036 & NS & NS \\
\hline CPT-1 & 0.79 & 0.02 & 0.80 & 0.01 & 0.74 & 0.02 & 0.73 & 0.01 & 0.001 & NS & NS \\
\hline $\mathrm{AOX}$ & 0.90 & 0.05 & 0.87 & 0.02 & 0.80 & 0.04 & 0.81 & 0.03 & 0.038 & NS & NS \\
\hline TAG $(\mu \mathrm{g} / \mathrm{g}$ tissue $)$ & 33.3 & 7.1 & 30.5 & 6.4 & 71.3 & 5.3 & 71.6 & 8.3 & $<0.0001$ & NS & NS \\
\hline
\end{tabular}

MD, maternal diet. *Normalised cycle threshold.

It has been shown for the first time that the maternal PR diet reduces PPAR $\alpha$ expression in the offspring. This is accompanied by reduced expression of key target genes in fatty acid $\beta$-oxidation, which is consistent with higher TAG deposition. Together these findings suggest that an overall $26 \%$ reduction in PPAR $\alpha$ P1 and P2 expression induced by maternal undernutrition during pregnancy may restrict the range of substrates for energy production and alter lipid composition in the heart, and so constrain its functional capacity.

The study was funded by the British Heart Foundation, who also provided salary support for J.S.-J., G.B. and M.H.

1. Finck BN, Han X, Courtois M, Aimond F, Nerbonne JM, Kovacs A, Gross RW \& Kelly DP (2003) Proc Natl Acad Sci USA 100, $1226-1231$.

2. Langley-Evans SC (2001) Proc Nutr Soc 60, 505-513.

3. Burdge GC, Slater-Jefferies JL, Grant RA, Chung WS, West AL, Lillycrop KA, Hanson MA \& Calder PC (2008) Prostaglandins Leukot Essent Fatty Acids 78, 73-79. 